\title{
Cost of Treating Maternal Complications and Associated Factors in Mekelle General Hospital, Northern Ethiopia
}

This article was published in the following Dove Press journal: Risk Management and Healthcare Policy

\author{
Teamir Abadi ${ }^{\prime}$ \\ Anagaw Derseh Mebratie (iD ${ }^{2}$ \\ 'Health Bureau Health Care Financing \\ Reform Case Team, Tigray Regional \\ Health Bureau, Mekelle, Ethiopia; ${ }^{2}$ School \\ of Public Health, Addis Ababa University, \\ Addis Ababa, Ethiopia
}

Background: The government of Ethiopia introduced an exemption policy that guarantees free maternal healthcare services from public providers. This policy aims to ensure financial protection and enhance utilization of services especially for low-income people. However, patients in most cases incur health expenditure when seeking health care. This paper aims to assess direct and indirect medical costs of treating maternal complications and associated factors at a public hospital in Northern Ethiopia.

Methods: An institution-based cross-sectional study design was carried on 267 mothers with complications. A multivariate linear regression model at 5\% level of significance was used to analyze factors driving the outcome.

Results: The median cost was more than seven times the monthly minimum wage, and this may cause severe financial consequences for the poor. Direct medical costs accounted for the major share $(68 \%)$ of total cost, and this was mainly driven by lack of diagnostic services at public facilities and paying for private providers. Expenditure for treatment of maternal complications is positively associated with income, absence from work, travel time to the facility and being diagnosed at a private facility.

Conclusion: The overall evidence in this study poses a concern about the context in which fee exemption reforms are being implemented.

Keywords: maternal complications, treatment, direct and indirect costs, Mekelle, Ethiopia

\section{Introduction}

The global maternal mortality ratio (MMR), despite remarkable progress in recent years, is still unacceptably high. In 2017, about 295,000 women died because of pregnancy and childbirth-related complications. Of these, 94\% of deaths occurred in low and middle-income countries and Sub-Saharan African alone accounted for about two-thirds $(196,000)$ of maternal deaths. Moreover, 15 million women annually develop long-term disabilities caused by such health problems. ${ }^{1-3}$ Young adolescents between ages 10 and 14 face the highest risk of maternal complications and deaths. The major causes of maternal deaths in Africa are infections, postpartum hemorrhage, high blood pressure (preeclampsia and eclampsia), complications from delivery and unsafe abortion. ${ }^{2-5}$

Substantial expenditure due to maternal complications could create a heavy economic burden to the households. Even when medical services are offered at reasonable prices or free of charge, indirect medical expenses associated with treatment may constitute a larger proportion of household income. ${ }^{3,6}$ In addition,
Correspondence: Teamir Abadi

Tigray Regional Health Bureau, Mekelle, Ethiopia

Tel +251914423809

Fax +251344408830

Email teamirabadi2@gmail.com
Risk Management and Healthcare Policy 2021:14 87-95 
seeking treatment also leads to absenteeism in the workplace and thereby productivity loss. High health expenditure could result in incurring debts, selling of productive assets as well as reducing consumption of basic needs. ${ }^{7,8}$ Hence, the cost of treating maternal complications could be catastrophic for the poor and they may be pushed into further poverty. ${ }^{3}$

Ethiopia has one of the highest maternal death rates in Sub-Saharan Africa. In 2016, the MMR of the country was 412 per 100,000 live births which was above the minimum value of the WHO standard to classify MMR into the high group (that was 300 per 100,000 live births). The majority of the complications in Ethiopia are caused by limited use of skilled care and institutional delivery. Among the estimated 2.9 million women who give birth every year, only $26.2 \%$ deliver in health facilities. According to the 2016 Ethiopian Demographic and Health Survey (EDSH), the percentages of women who received antenatal care, delivery care and a postnatal check-up from skilled providers were $62.4 \%, 27.7 \%$ and $16.5 \%$, respectively. Poor quality of care also elevates rates of morbidity, mortality and cost of maternal complications in the country. ${ }^{9-14}$

In order to utilize modern care and reduce maternal and child mortality, the Government of Ethiopia introduced healthcare reforms in 2005. The reform guarantees access to maternal and child services free of charge from public facilities. However, due to shortages of different supplies and drugs, patients are usually referred to private providers and incur out-of-pocket health expenditure. Against the fee exemption proclamation, a number of government facilities also charge user fees for some services. ${ }^{15-17}$ This is because the facilities are not reimbursed for the services offered under the waiver policy and they face difficulties to cover operational costs.

Empirical evidence on the economic burden of diseases can inform the public policy agenda about healthcare priorities and healthcare budget allocations. Currently, there is limited research on the cost of treating maternal complications in low-income settings. The existing studies mainly measure costs of maternal care based on direct out-of-pocket health expenditure and do not account for opportunity costs of seeking treatment. ${ }^{18-20}$ Moreover, they did not investigate factors driving treatment costs. This study, therefore, aims to add knowledge to the literature by examining direct and indirect costs of treating maternal complications as well as associated factors in Northern Ethiopia.

\section{Methods}

\section{Study Area}

The study was conducted in Mekelle town which is located $783 \mathrm{~km}$ away from Addis Ababa, the capital city of Ethiopia. In 2017, a total of 412,938 people lived in Mekelle city with $23.5 \%$ being females in the reproductive age group (that is 15-49 years). In the same period, the number of pregnant mothers in the town was projected to be $12,333 .{ }^{21}$ Mekelle is one of the metropolitan areas in Ethiopia and it has seven sub-administrative units. The town has one teaching referral hospital, seven general hospitals and nine health centers. Moreover, there are 48 privately owned clinics.

\section{Data Collection}

The research was carried out in an institutional-based cross-sectional study design and a structured questionnaire was used to collect primary data. Considering previous estimates about out-of-pocket (OOP) expenditure for maternal care in Ethiopia with the $95 \%$ confidence interval and margin of error of $5 \%,{ }^{22}$ the study sampled 267 mothers. The study surveyed women with pregnancyrelated complications who gave birth at Mekelle General Hospital. Women with conditions of hemorrhage, preeclampsia and obstructed labor were eligible to participate in the study. During the survey days, all eligible women who were admitted at the study hospital were invited to take part in the study. Fewer than $2 \%$ of people declined to participate and they were replaced by other eligible women until the desired sample size $(\mathrm{N}=267)$ was met. The survey requested types of maternity complications encountered as well as direct and indirect costs of seeking treatment. Direct medical and non-medical costs were measured in terms of out-of-pocket expenditure and the study participants reported how much they spent for different items such as diagnosis, drugs, meals and transportation. In addition, the survey also collected information about demographic and socioeconomic characteristics of the respondents. Data collection took place between July 2018 and June 2019.

\section{Data Quality Assurance}

In order to ensure data quality, different measures were taken before and during field work. Since the local language in the study area is Tigrigna, the interviews were held in Tigrigna. The survey instrument was first prepared in English, translated into Tigrigna and then translated back into English to check for 
consistency. In addition, the instrument was pretested on 15 subjects ( $5 \%$ of estimated sample size) who were later excluded from the main study and necessary amendments were made to the tool. Prior to data collection, training was provided to data collectors and supervisors. Completeness of collected data was checked by supervisors on a daily basis. Close follow up and support were also provided by invigilators throughout the data collection process.

\section{Data Analysis}

Data were entered into Epienfo 7 and exported into SPSS version 21 for analysis. Descriptive statistics including percentage and frequency were used to portray the sociodemographic and clinical background of the study participants. The median and interquartile range (IQR) were estimated to show direct and indirect costs attributed to pregnancy complications. We preferred to use medians because health cost data are not often normally distributed and they are skewed to the right. Unlike the case of means, medians are not sensitive to the influence of outlier values and they are preferred in cost analysis. ${ }^{23}$

To examine factors associated with the cost of treating complications, first bivariate linear regression analyses were conducted. The regression model controlled for a number of individual characteristics including age, household size, education, occupation, monthly individual income and residency. It also accounted for type of maternal complication, number of pregnancies, mode of delivery, frequency of ANC visits, number of laboratory tests, facility of diagnosis, number of days being absent from work and transportation time. Then, those covariates with $p$-values of less than 0.25 were included in the multivariate regression model. Finally, statistical significance was determined at $p$-values less than 0.05 and with $95 \%$ CI.

\section{Cost Valuation Method}

The study identified direct and indirect costs of treatment during the hospital admission associated with maternal complications. Direct costs comprise expenditure for both medical and non-medical purposes. Direct medical costs include spending for diagnosis, medical supplies, drugs and consultation. Medical spending includes payment before and after delivery to get treatment at a public hospital and to be diagnosed at any providers during the hospital admission. Direct non-medical costs indicate expenditure for food, accommodation and transportation. Non-medical costs include spending for the patient as well as for accompanying individuals.
Unlike the majority of the existing studies, ${ }^{24,25}$ indirect costs caused by absence from work and thereby productivity loss were also computed. Using a human capital approach, ${ }^{26}$ the value of productivity loss was estimated by multiplying daily income of the women with number of days being absent from work for treatment and recovery. The opportunity costs for accompanying family members were also calculated using a similar approach. The value of a labor day (the minimum wage rate) was used to convert the workdays lost into a monetary value for those who did not have any occupation during the study period. According to the National Labor Force Survey (NLFS) report, the monthly minimum wage rate for an agricultural worker was Ethiopian Birr (ETB) 697 $(\mathrm{US} \$ 24){ }^{27}$

\section{Ethical Considerations}

Ethical approval was obtained from the Institutional Review Board (IRB) of Addis Ababa University College of Health Sciences. In addition, permission was also obtained from Mekelle General Hospital. Respondents were informed about the purpose of the study and confidentiality of the information collected for this research. Interviewees were told about their right to withdraw from the study at any time if they felt uncomfortable. Finally, those who provided verbal consent participated in this research. The verbal informed consent was approved by the IRB of Addis Ababa University College of Health Sciences. Moreover, IRB approved respondents aged $15-17$ years to provide informed consent on their own behalf. The authors confirm that the study protocols used in this study met the Declaration of Helsinki principles.

\section{Results}

\section{Socio-Demographic Characteristics of Study Participants}

A total of 267 mothers with pregnancy-related complications participated in this study. The majority of them were married (94.8\%), Orthodox Christian (84.6\%) and Tigray ethnic group (94.8\%). About $78 \%$ of the participants were 25-34 years old while only 6\% were above 34 years. In terms of educational attainment, about $89 \%$ of individuals attended some form of formal education while $11 \%$ of them were not in school at all. About $80 \%$ of the women earned less than or equal to 
Table I Socio-Demographic Characteristics of Sample Women $(\mathrm{N}=267)$

\begin{tabular}{|c|c|c|c|}
\hline Variables & Category & Frequency & Percentage \\
\hline \multirow[t]{3}{*}{ Age (in years) } & $15-24$ & 43 & 16.1 \\
\hline & $25-34$ & 207 & 77.5 \\
\hline & $35-49$ & 17 & 6.4 \\
\hline \multirow[t]{2}{*}{ Marital status } & Married & 253 & 94.8 \\
\hline & Single & 14 & 5.2 \\
\hline \multirow[t]{2}{*}{ Ethnicity } & Tigray & 253 & 94.8 \\
\hline & Amhara & 14 & 5.2 \\
\hline \multirow[t]{4}{*}{ Occupation } & $\begin{array}{l}\text { Government } \\
\text { worker }\end{array}$ & 85 & 31.8 \\
\hline & Merchant & 61 & 22.8 \\
\hline & Housewife & 100 & 37.5 \\
\hline & Others & 21 & 7.8 \\
\hline \multirow[t]{3}{*}{ Education } & $\begin{array}{l}\text { Unable to } \\
\text { read and } \\
\text { write }\end{array}$ & 29 & 10.8 \\
\hline & $\begin{array}{l}\text { Primary and } \\
\text { secondary }\end{array}$ & 119 & 44.6 \\
\hline & $\begin{array}{l}\text { Diploma and } \\
\text { above }\end{array}$ & 119 & 44.6 \\
\hline \multirow[t]{2}{*}{ Religion } & Orthodox & 226 & 84.6 \\
\hline & Muslim & 41 & 15.4 \\
\hline \multirow{5}{*}{$\begin{array}{l}\text { Monthly income of } \\
\text { woman (in ETB) }\end{array}$} & $<1001$ & 74 & 27.7 \\
\hline & $100 \mid-3000$ & 77 & 28.8 \\
\hline & $300 \mathrm{I}-5000$ & 62 & 23.2 \\
\hline & $500 \mathrm{I}-7000$ & 31 & 11.6 \\
\hline & $>7000$ & 23 & 8.6 \\
\hline
\end{tabular}

ETB 5000 per month. The demographic and socioeconomic characteristics of study participants are reported in Table 1.

\section{Clinical Characteristics of Study Participants}

Among sample mothers, 106 (39.7\%) suffered from preeclampsia while the rest were affected by hemorrhage $(30.3 \%)$ and obstructed labor $(30 \%)$. The data show that $123(46.1 \%)$ women delivered by spontaneous vaginal delivery (SVD) and 177 (66.3\%) were
Table 2 Clinical Characteristics of Patients

\begin{tabular}{|c|c|c|c|}
\hline Variables & Category & Frequency & Percentage \\
\hline \multirow{3}{*}{$\begin{array}{l}\text { Type of } \\
\text { complication }\end{array}$} & Hemorrhage & 81 & 30.3 \\
\hline & Preeclampsia & 106 & 39.7 \\
\hline & $\begin{array}{l}\text { Obstructed } \\
\text { labor }\end{array}$ & 80 & 30.0 \\
\hline \multirow[t]{3}{*}{ Mode of delivery } & Instrumental & 29 & 10.9 \\
\hline & SVD & 123 & 46.1 \\
\hline & $\begin{array}{l}\text { Cesarean } \\
\text { section }\end{array}$ & 115 & 43.1 \\
\hline \multirow[t]{5}{*}{ Para } & One & 90 & 33.8 \\
\hline & Two & 57 & 21.3 \\
\hline & Three & 68 & 25.5 \\
\hline & Four & 31 & 11.6 \\
\hline & Five and above & 21 & 7.9 \\
\hline \multirow[t]{2}{*}{ Site of diagnosis } & In the hospital & 178 & 66.7 \\
\hline & $\begin{array}{l}\text { Out of the } \\
\text { hospital }\end{array}$ & 89 & 33.3 \\
\hline \multirow{4}{*}{$\begin{array}{l}\text { Frequency of ANC } \\
\text { visits }\end{array}$} & Twice & 8 & 3.0 \\
\hline & Three times & 32 & 12.0 \\
\hline & Four times & 152 & 56.9 \\
\hline & Above four & 75 & 28.1 \\
\hline \multirow[t]{2}{*}{ Gravid } & Primigravida & 90 & 33.7 \\
\hline & Multigravida & 177 & 66.3 \\
\hline \multirow{3}{*}{$\begin{array}{l}\text { Transportation } \\
\text { modality }\end{array}$} & On foot & 9 & 3.4 \\
\hline & $\begin{array}{l}\text { Public } \\
\text { transportation }\end{array}$ & 174 & 65.2 \\
\hline & Ambulance & 84 & 31.4 \\
\hline
\end{tabular}

multigravida mothers. Even if all patients received treatment at Mekelle public hospital and no one used private care, about $33 \%$ had diagnosed their complications at private facilities. The proportion of women who attended antenatal care (ANC) four times was $56.9 \%$ (Table 2). In order to come to the health facility, public transportation modality was mostly used.

\section{Costs of Treating Maternal Complications}

The median total cost of treating a complication among the study group was ETB 5120 (IQR=2325) (Table 3). As 
Table 3 Costs of Maternal Complication Treatment (in ETB)

\begin{tabular}{|c|c|}
\hline Type of Cost & Median (IQR) \\
\hline \multicolumn{2}{|l|}{ Direct medical cost } \\
\hline Laboratory cost & $1180.01(608.13)$ \\
\hline Drug and consultation & 2299.99 (1392.00) \\
\hline Total & $3480.00(1256.57)$ \\
\hline \multicolumn{2}{|l|}{ Direct non-medical cost } \\
\hline Food cost & $309.14(296.96)$ \\
\hline Transportation cost & $299.86(291.16)$ \\
\hline Total & $609.00(564.63)$ \\
\hline Indirect cost due to productivity lost & $1030.95(615.67)$ \\
\hline Total cost & $5119.95(2325.22)$ \\
\hline
\end{tabular}

shown in Figure 1, the majority of the study participants spent between ETB 4000 and ETB 6000.

The result shows that women in the upper income group paid more for treatment of maternal complications. On average, women in the bottom income group spent ETB 1133 while those in the top income group paid ETB 5855 due to pregnancy-related complications (Figure 2).

Direct medical spending (median=ETB 3480) for drug and diagnostic tests constitutes the major share out of total health expenditure.

Of the 267 study participants, the median direct nonmedical cost incurred to attend health services was ETB
609 (IQR=565). This includes food and transportation expenditure made by the households. Furthermore, indirect costs due to lost productivity while attending treatment amounted to ETB 1031. Indirect costs of seeking treatment constitute $20 \%$ of total treatment costs (Figure 3).

Disaggregating costs by complications, spending for obstructed labor (median=ETB 5293; IQR=2279.4) was higher than hemorrhage (median=ETB 4735; IQR=2073.5) (Table 4). Regardless of the alternative cases, direct medical costs accounted for the largest proportion of total cost which ranges from ETB 3201 for hemorrhage to ETB 3782 for obstructed labor. The opportunity cost of seeking treatment is found to be a bit higher for preeclampsia complication (ETB 856).

\section{Factors Driving Treatment Cost}

The study investigates factors driving treatment cost using linear regression models. The outcome variable includes direct and indirect costs of treating pregnancy complications. From binary analysis, a number of household characteristics and health supply factors were associated with the cost of treatment. However, in the multivariate regression, monthly income of the individual, number of laboratory tests, the facility of diagnosis, number of days absent and transportation time were the only statistically significant predictors (at $p$-value 0.05 ).

It is found that, holding other covariates constant, women with monthly income of ETB 1001-3000 incur ETB 9.2 higher for treatment of complication than those

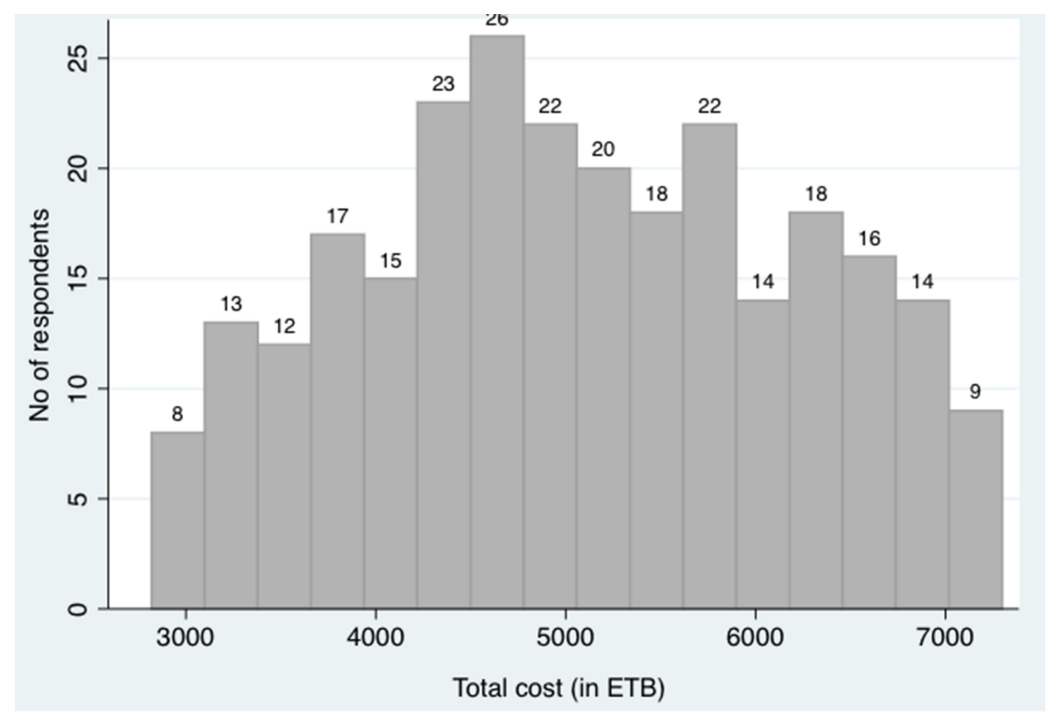

Figure I Distribution of total treatment costs incurred by the respondents. 


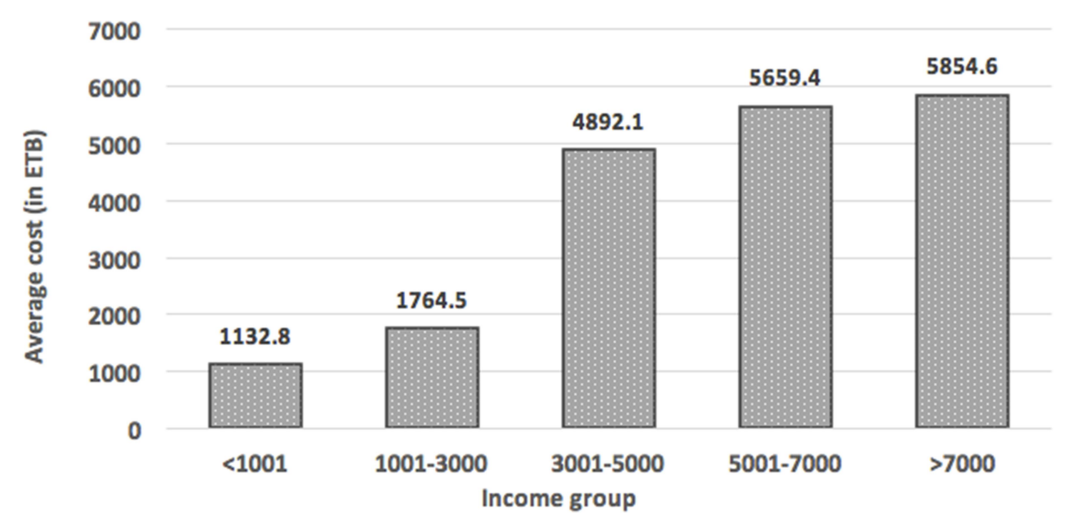

Figure 2 Average total cost of treatment by income group (in ETB).

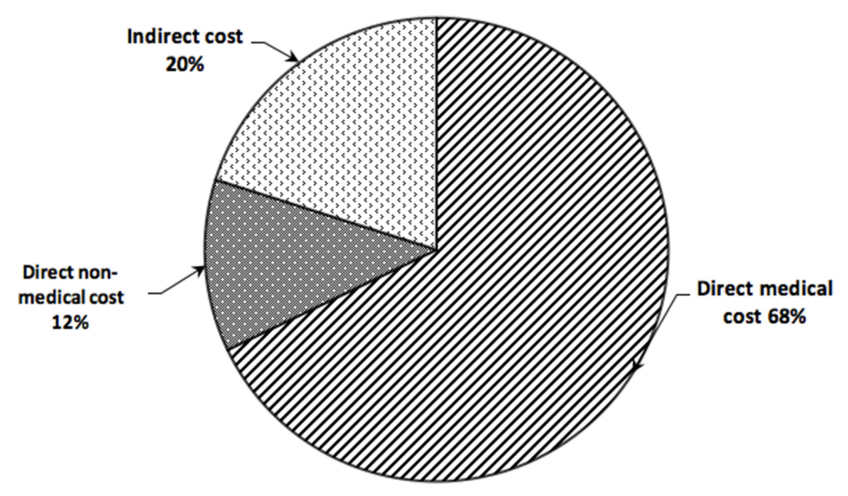

Figure 3 Share of direct and indirect costs of treating maternal complications.

earning ETB $\leq 1000$ (Table 5). The payment for those who earn above ETB 7009 is more by about ETB 52.4 as compared to those in the reference group. The result also shows that when the number of laboratory tests increases by one, cost of treatment rises by about ETB 5 .

Obtaining diagnosis services at a private facility leads to additional health expenditure of ETB 26. Furthermore, absence from work for 10 days while obtaining treatment for complications causes about ETB 43 extra cost. The analysis also shows a direct and statistically significant association between travel time and health expenses.

\section{Discussion}

Many women lose their lives and others develop long-term disabilities each year due to pregnancy and childbirthrelated complications. In addition to health problems, they also face huge economic challenges. This study assesses the financial burden and associated factors of maternal complications in Ethiopia where the MMR is unacceptably high. In order to do so, it uses an institutionbased cross-sectional study design and data were collected from Mekelle General Hospital.

The result reveals that, despite the country's healthcare financing policy that guarantees access to maternal services free of charge, women with maternal complications incur health expenditure. The median costs among those who were attending services at the study hospital were ETB 5120 (US\$176.8). Disaggregating costs by type of complication, health spending for obstructed labor was relatively higher than hemorrhage cases. This is because treatment of obstructed labor requires cesarean section and costly medications as well as work absentieseem. The median cost (ETB 5120) of treatment in the sample was more than seven times the monthly minimum wage (ETB 697) in Ethiopia. ${ }^{27}$ Medium cost incurred among the study participants was compared with the minimum wage

Table 4 Costs by Type of Complications (in ETB)

\begin{tabular}{|c|c|c|c|c|c|}
\hline \multirow[t]{2}{*}{ Type of Complication } & \multirow{2}{*}{$\begin{array}{l}\text { Number of } \\
\text { Women } \\
\text { Suffered by the } \\
\text { Case }\end{array}$} & \multicolumn{4}{|l|}{ Median Cost (IQR) } \\
\hline & & Direct Medical Cost & Direct Non-Medical Cost & Indirect Cost & Total Cost \\
\hline Hemorrhage & 81 & $3200.73(1236.56)$ & $599.72(475.60)$ & $756.00(1287.02)$ & $4735.70(2073.50)$ \\
\hline Preeclampsia & 106 & $3399.67(|3| 0.5 \mid)$ & $613.93(564.63)$ & 855.79 (I263.24) & $5280.90(2765.73)$ \\
\hline Obstructed labor & 80 & 3781.89 (1485.96) & 705.86 (590.73) & 783.00 (1279.19) & $5292.50(2279.40)$ \\
\hline
\end{tabular}


Table 5 A Multivariate Analysis of Factors Associated with Cost of Treating Maternal Complication ( $\mathrm{N}=267)$

\begin{tabular}{|c|l|l|l|}
\hline Variable & Coef & Std Err & $\begin{array}{l}\text { p > } \\
(\mathbf{t})\end{array}$ \\
\hline \multicolumn{2}{|l|}{ Monthly income of woman (in ETB) } & \multicolumn{2}{l|}{} \\
\hline I00I-3000 (ref: <100I) & 9.195820 & 8.416831 & 0.010 \\
\hline $3001-5000$ & 39.83815 & 8.64382 & 0.000 \\
\hline $5001-7000$ & 51.17361 & 10.3626 & 0.000 \\
\hline$>7000$ & 52.3724 & 15.61741 & 0.000 \\
\hline Number of laboratory tests & 4.872163 & 3.102209 & 0.016 \\
\hline Facility of diagnosis & & & \\
\hline $\begin{array}{l}\text { Private provider (ref: public } \\
\text { hospital) }\end{array}$ & 25.58213 & 6.58497 & 0.001 \\
\hline $\begin{array}{l}\text { Number of days absent from } \\
\text { work }\end{array}$ & 4.26547 & 1.462394 & 0.012 \\
\hline Transport time (in hours) & 1.0007916 & 0.2816371 & 0.000 \\
\hline
\end{tabular}

Note: Only statistically significant predictors of the outcome are reported.

because health expenditures for the lowest income group of women may be too low as they may forgo necessary care. The analysis indicates that expenditure on maternal complications could not only deplete household resources, but also negatively impact the ability of the poor households to meet subsistence needs. ${ }^{28}$

The cost of treating maternal complications in this study is higher than case studies in Northern Ghana (US \$32) and India (US\$145) but lower than evidence in Nigeria (US\$ 243.8) and Bangladesh (US\$ 261). ${ }^{28-31}$ In addition to context-specific variations across the study areas, these differences are partly due to alternative methods of analysis and definition of the outcomes. Unlike many studies, costs of treatment in this research include both direct health spending and opportunity costs. Direct costs include payments for consultation, diagnosis and drugs. Out-of-pocket health expenditure contains payments to access services at public hospital as well as private providers.

The median direct medical cost paid for consultation, diagnosis and drugs was ETB 3480 and this constituted the largest share $(68 \%)$ of total expenses. Because of the fee waivers arrangement, none of the sample women reported health spending to access services at Mekelle General Hospital. Due to shortage of drugs and lack of diagnosis services at the study public hospital, about $33 \%$ of patients were referred to private providers and incurred OOP health expenditure. Total spending for private care constituted $37 \%$ of total costs and treatment expenses were substantially higher for those patients who used private providers. The policy implication of this evidence is the need to ensure availability of necessary medical equipment, laboratory detergents and drugs at public providers to reduce the incidence of catastrophic health spending. Studies from limited resource settings with high maternal mortality also reveal the cost-effectiveness of providing treatment for complications using a high dependence unit and intensive care unit at public hospitals. ${ }^{32,33}$

Not only medical expenses, but direct non-medical costs could also create an economic burden. ${ }^{28,30}$ Costs related to transportation, accommodation, food and other expenses can be catastrophic if patients have to travel a long distance and wait a long time to access services. Among study participant women, median costs were ETB 300 for transportation and ETB 309 for food. Expanding coverage of medical care can help to reduce costs attributed due to living far from health facilities.

The study shows that indirect costs (median=ETB 1031) are the second main costs of seeking treatment. Attending treatment leads to productivity loss for the patient and accompanying family members. Hence, indirect costs can create a strong barrier in utilization of services especially when the women are the breadwinners to their families. ${ }^{24}$

Multivariate regression analysis reveals that socioeconomic status strongly predicts payment for treatment. It is found that those who get higher income are more likely to spend more to access services. This is because mothers with better income can afford to use services whenever needed. They may also prefer quality care and branded drugs even if prices are expensive. ${ }^{19,31,34}$ On the other hand, the poor may have forgone care due to limited ability to afford medical costs especially if they are referred to use private care.

There is a direct association between the number of laboratory tests and expenditure for health care. This is similar to a study in Nigeria showing the adverse effect of laboratory tests and blood transfusion services on the cost of care. ${ }^{30}$ Similar to the studies conducted in Africa and Asia, the site of diagnosis also influences health expenditure. ${ }^{18,19,28}$ Mothers who were referred to private facilities had spent higher costs.

The overall evidence in this study raises a concern about the context in which fee exemption policies are 
being implemented. Maternal services are supposed to be provided free of charge in Ethiopia but costs incurred by the households to assess care are still high. This is mainly due to supply-side constraints including lack of diagnosis services and shortage of drugs at public facilities. In addition, the households also face substantial non-medical costs and productivity loss.

\section{Conclusion}

The evidence in this study implies that fee waiver policies for maternal services may not provide adequate financial protection against catastrophic health expenditure. In order to make these policies more effective, it is necessary to expand coverage of health infrastructure and ensure availability of essential medical services and drugs at public facilities. Referring the poor to private health providers could have major economic consequences. Furthermore, distance to the facilities could be a barrier to access services. A long travel distance causes higher spending for transportation and food. In the meantime, this also increases workplace absentieseem and productivity loss.

The findings of this paper should be considered subject to some limitations. First, this is institutional-based research and may not be representative of the population in the study area. Second, due to recall bias, some expenditure and income could be overestimated or underestimated. Third, indirect cost estimates did not include intangible costs attributed to complication pain, psychological pressure, reduced joy of life and social prestige. Although such cost components are important, it is difficult to measure them and they are not usually included in health cost estimates (eg 20, 28, 30, 31). Finally, even if various socioeconomic variables were controlled in the regression analysis, there could be still uncontrolled confounders that drive the outcome.

\section{Acknowledgments}

We would like to acknowledge that this manuscript is based on a thesis submitted to School of Public Health at Addis Ababa University in partial fulfillment of the requirements for the Degree of Master of Public Health in Health Economics. The authors are grateful to Alemtsehay Tewelde from Mekelle University and health experts at Tigray Regional Health Bureau for their constructive comments and advice. Last but not least, thank you to all respondents, data collectors and supervisors for taking part in this study.

\section{Disclosure}

The authors report no conflicts of interest for this work.

\section{References}

1. World Health Organization. Evaluating the Quality of Care for Severe Pregnancy Complications the WHO Near-Miss Approach for Maternal Health. Geneva: WHO Press; 2011.

2. World Health Organization. UNICEF, UNFPA, World Bank Group, the United Nations Population Division. Trends in Maternal Mortality 2000 to 2017. WHO report; 2019.

3. World Health Organization. UNICEF, UNFPA, World Bank Group, the United Nations Population Division. Trends in Maternal Mortality 1990 to 2013. WHO report; 2014.

4. Gennaro FD, Marotta C, Pisani L, et al. Maternal caesarean section infection (MACSI) in Sierra Leone: a case-control study. Epidemiol Infect. 2020;148.

5. Marotta C, Pisani L, Gennaro FD, et al. Epidemiology, outcomes, and risk factors for mortality in critically ill women admitted to an obstetric high-dependency unit in Sierra Leone. Am J Trop Med Hyg. 2020;103(5):2142-2148. doi:10.4269/ajtmh.20-0623

6. Storeng KT, Murray SF, Akoum MS, Ouattara F, Filippi V. Beyond body counts: a qualitative study of lives and loss in Burkina Faso after 'near-miss' obstetric complications. Soc Sci Med. 2010;71 (10):1749-1756. doi:10.1016/j.socscimed.2010.03.056

7. Russell S. The economic burden of illness for households in developing countries: a review of studies focusing on malaria, tuberculosis, and human immunodeficiency virus/acquired immunodeficiency syndrome. Am J Trop Med Hyg. 2004;71(2_suppl):147-155. doi:10.4269/ajtmh.2004.71.147

8. Wagner AK, Graves AJ, Reiss SK, Lecates R, Zhang F, RossDegnan D. Access to care and medicines, burden of health care expenditures, and risk protection: results from the World Health Survey. Health Policy (New York). 2011;100(2-3):151-158. doi:10.1016/j.healthpol.2010.08.004

9. Central Statistical Agency (CSA) [Ethiopia], ICF. Ethiopia Demographic and Health Survey 2016. Addis Ababa, Ethiopia, and Rockville, Maryland, USA: CSA and ICF; 2016.

10. Abadi T. Cost of Treating Maternal Complications Among Mothers Attending Mekelle General Hospital in Mekelle City, Tigray, Ethiopia [Master's thesis]. 2019. Available from: http://etd.aau.edu.et/handle/ 123456789/20902. Accessed December 11, 2020.

11. Gaym A. Maternal mortality studies in Ethiopia-magnitude, causes and trends. Ethiop Med J. 2015;47(2):95-108.

12. Tessema GA, Laurence CO, Melaku YA, et al. Trends and causes of maternal mortality in Ethiopia during 1990 - 2013: findings from the global burden of diseases study 2013. BMC Public Health. 2017;17:1-8. doi:10.1186/s12889-017-4071-8

13. Austin A, Gulema H, Belizan M, et al. Barriers to providing quality emergency obstetric care in Addis Ababa, Ethiopia: healthcare providers' perspectives on training, referrals and supervision, a mixed methods study. BMC Pregnancy Childbirth. 2015;15(1). doi:10.1186/ s12884-015-0493-4

14. Liyew EF, Yalew AW, Afework MF, Essén B, Gurgel RQ. Incidence and causes of maternal near-miss in selected hospitals of Addis Ababa, Ethiopia. PLoS One. 2017;12(6):e0179013. doi:10.1371/journal.pone. 0179013

15. Federal Ministry of Health. The Essential Package of Health Services in Ethiopia. Addis Ababa: Planning and Programming Department, Federal Ministry of Health; 2005.

16. Alebachew L, Mitiku W, Mann C, Berman P. Exempted Health Services in Ethiopia: Cost Estimates and Its Financing Challenges. Boston and Addis Ababa: Harvard T.H. Chan School of Public Health and Breakthrough International Consultancy PLC; 2018. 
17. Pearson L, Gandhi M, Admasu K, Keyes EB. User fees and maternity services in Ethiopia. Int J Gynaecol Obstet. 2011;115(3):310-315. doi:10.1016/j.ijgo.2011.09.007

18. Akalu T, Guda A, Tamiru M, Mariam DH. Examining out of pocket payments for maternal health in rural Ethiopia: paradox of free health care un-affordability. Health Dev. 2012;26(1):1-7.

19. Goli S, Rammohan A. Out-of-pocket expenditure on maternity care for hospital births in Uttar Pradesh, India. Health Econ Rev. 2018;8 (1). doi:10.1186/s13561-018-0189-3

20. Myint ANM, Liabsuetrakul T, Htay TT, Wai MM, Sundby J, Bjertness E. Impoverishment and catastrophic expenditures due to out-of-pocket payments for antenatal and delivery care in Yangon Region, Myanmar: a cross-sectional study. BMJ Open. 2018;8:11. doi:10.1136/bmjopen-2018-022380

21. Tela FG, Bezabih AM, Adhanu AK, Bazzano AN. Effect of pregnancy weight gain on infant birth weight among mothers attending antenatal care from private clinics in Mekelle City, Northern Ethiopia: a facility based follow-up study. PLoS One. 2019;14(3): e0212424. doi:10.1371/journal.pone.0212424

22. Islam K, Gerdtham U. The Cost of Maternal-Newborn Illness and Mortality. Geeva: World Health Organization; 2016.

23. Kappelman MD, Rifas-Shiman SL, Porter CQ, et al. Direct health care costs of Crohn's disease and ulcerative colitis in US children and adults. Gastroenterology. 2008;135(6):1907-1913. doi:10.1053/j. gastro.2008.09.012

24. Shwe ATW, Riewpaiboon A, Chaikledkaew U, Youngkong S, Hackney DN. Treatment cost and costing model of obstetric complications at a hospital in Myanmar. PLoS One. 2019;14(3):e0213141. doi:10.1371/journal.pone.0213141

25. Ashrafedin Y. Estimating the Cost of Maternal and Child Health Services in Primary Health Care Facilities Around Butajira. Addis Ababa: Addis Ababa University; 2014:1-88.
26. World Health Organization. WHO Guide to Identifying the Economic Consequences of Disease and Injury. Geneva: Dept. of Health Systems; 2009.

27. Mehran F, Consultant ILO, Ozel MH, et al. Yemen labour force survey 2013-14 1 International Labour Organization regional office for Arab States. 5-176.

28. Dalaba MA, Akweongo P, Aborigo RA, et al. Cost to households in treating maternal complications in northern Ghana: a cross sectional study. BMC Health Serv Res. 2015;15(1):1-8. doi:10.1186/s12913014-0659-1

29. Govil D, Purohit N, Gupta SD, Mohanty SK. Out-of-pocket expenditure on prenatal and natal care post Janani Suraksha Yojana: a case from Rajasthan, India. J Health Popul Nutr. 2016;35:1.

30. Adamu AN, Adamu H, Isa AY, Zubairu S. Expenditure on emergency obstetric care in a federal tertiary institution in Nigeria. $J$ Womens Health Care. 2013;02:04.

31. Hoque ME, Jackson TP, Dasgupta SK, Chowdhury ME, Koblinsky M. Costs of maternal health-related complications in Bangladesh. J Health Popul Nutr. 2012;30(2). doi:10.3329/jhpn. v30i2.11315

32. Marotta C, Gennaro FD, Pisani L, et al. Cost-utility of intermediate obstetric critical care in a resource-limited setting: a value-based analysis. Ann Glob Health. 2020;86(1):82. doi:10.5334/aogh.2907

33. Cubro H, Somun-Kapetanovic R, Thiery G, Talmor D, Gajic O. Cost effectiveness of intensive care in a low resource setting: a prospective cohort of medical critically ill patients. World J Crit Care Med. 2016;5(2):150. doi:10.5492/wjccm.v5.i2.150

34. Kalu-umeh NN, Mph M, Sambo MN, Fwacp M, Idris SH. Costs and patterns of financing maternal health care services in rural communities in Northern Nigeria: evidence for designing national fee exemption policy. Int $J$ MCH AIDS. 2013;2(1):163-172.
Risk Management and Healthcare Policy

\section{Publish your work in this journal}

Risk Management and Healthcare Policy is an international, peerreviewed, open access journal focusing on all aspects of public health, policy, and preventative measures to promote good health and improve morbidity and mortality in the population. The journal welcomes submitted papers covering original research, basic science, clinical \& epidemiological studies, reviews and evaluations, guidelines, expert opinion and commentary, case reports and extended reports. The manuscript management system is completely online and includes a very quick and fair peer-review system, which is all easy to use. Visit http://www.dovepress.com/testimonials.php to read real quotes from published authors. 